\title{
Modeling the retention of rumen boluses for the electronic identification of goats
}

\author{
S. Carné, ${ }^{\star}$ G. Caja, ${ }^{\star 1}$ J. J. Ghirardi, ${ }^{2}$ and A. A. K. Salama ${ }^{\star} \dagger$ \\ *Grup de Recerca en Remugants (G2R), Departament de Ciència Animal i dels Aliments, Universitat Autònoma de Barcelona, 08193 Bellaterra, \\ Spain \\ †Sheep and Goat Research Department, Animal Production Research Institute, 12311 Dokki, Giza, Egypt
}

\begin{abstract}
We constructed a regression model to estimate the retention of electronic boluses in goats. With this aim, 2,482 boluses were administered to goats from dairy (Murciano-Granadina, $\mathrm{n}=1,326$; French Alpine, $\mathrm{n}=$ 381 ) and meat (Blanca de Rasquera, $\mathrm{n}=532$ ) breeds. A total of 19 bolus types made of materials (ceramic, plastic tubes filled with concrete or silicone, and ballasts) differing in their specific gravity (SG) were used, thereby obtaining a wide variation in bolus features: diameter ( 9 to $22 \mathrm{~mm}$ ), length ( 37 to $84 \mathrm{~mm}$ ), weight (5 to $111 \mathrm{~g}$ ), volume (2.6 to $26 \mathrm{~mL}$ ), and SG (1.0 to 5.5 ). Each bolus contained a half-duplex glass encapsulated transponder $(32 \times 3.8 \mathrm{~mm})$ and was administered using adapted balling guns. Murciano-Granadina and Blanca de Rasquera goats also wore 2 visual plastic ear tags: V1 (double flag, $5.1 \mathrm{~g}$ ) and V2 (flag-button, $4.2 \mathrm{~g}$ ). No data on ear tags in French Alpine goats was available. Bolus and ear tag retention [(retained/monitored) $x$ 100] was recorded for at least 1 yr. Dynamic reading efficiency [(dynamic reading/static reading $) \times 100]$ was also evaluated from 1,496 bolus readings. No administration incidences or apparent negative behavior or performance effects were observed for any bolus type. Static reading efficiency of retained boluses was $100 \%$, except for the prototypes with metal ballasts, which yielded a $93.3 \%$ reading efficiency. Retention of metalballasted boluses was confirmed using x-ray equipment. Excluding ballasted boluses, a 99.5\% dynamic reading efficiency was obtained. Ear tag losses were $6.5 \%$ for $\mathrm{V} 1$ and $3.7 \%$ for $\mathrm{V} 2$, ranging from 3.2 to $7.8 \%$ depending on ear tag type and goat breed. Bolus retention varied (0 to 100\%) according to their physical features. Obtained data allowed the fitting of a logistic model of bolus retention rate according to bolus volume and weight $\left(\mathrm{R}^{2}=0.98\right)$; the $\mathrm{SG}$ was implicitly considered.
\end{abstract}

\footnotetext{
Received February 26, 2010.

Accepted August 30, 2010.

${ }^{1}$ Corresponding author: gerardo.caja@uab.cat

${ }^{2}$ Current address: Shearwell Data Ltd., Mariano Acosta 215, 1842 Buenos Aires, Argentina.
}

Estimated weight and SG to produce medium- $(15 \mathrm{~mL})$ and standard-sized $(22 \mathrm{~mL})$ boluses for $99.95 \%$ retention rate in goats were 73.0 and $94.1 \mathrm{~g}$, and 4.87 and 4.28, respectively. Mini-boluses are not recommended, as none of the available radio translucent materials reach the required SG. In conclusion, increase of SG was fundamental to optimize bolus retention. Mediumsized boluses (10 to $15 \mathrm{~mL}$; SG 5.8 to 4.9 ) for early administration and efficient retention in adult goats could be produced, thereby addressing the problem of using proper boluses for goat identification.

Key words: electronic identification, goat, rumen bolus, transponder

\section{INTRODUCTION}

During the last years, several passive radiofrequency identification (RFID) devices have been tested to electronically identify domestic ruminants, including injectable transponders in different body locations (Fonseca et al., 1994; Lambooij et al., 1999), rumen boluses (Caja et al., 1999a; Fallon et al., 2002; JRC, 2003), ear tags (Schuiling et al., 2004; Carné et al., 2009a), and leg bands (Abecia and Torras, 2009; Carné et al., 2009b, 2010). Rumen boluses have proved to be easily administered and show a suitable long-term retention when properly designed and administered in sheep and cattle (Hasker and Bassingthwaighte, 1996; Teyssier et al., 2003; Ghirardi et al., 2006a,b). In this sense, small boluses ( 5 to $6.5 \mathrm{~mL}$ ) have been successfully used to permanently identify lambs at early ages (Garín et al., 2005; Ghirardi et al., 2007). Identification performances and advantages of using RFID transponders in the form of subcutaneous injects or boluses, compared with visual ear tags, for milk recording in dairy goats were previously reported by Caja et al. (1999b) and Ait-Saidi et al. (2008), respectively.

A relationship between physical features of boluses and their retention rate in the reticulorumen has been noted by different authors (Ribó et al., 1994; Caja et al., 1999a; Fallon, 2001). More recently, the possibility of satisfactorily predicting the retention of boluses 
according to their physical features in both cattle and sheep has been modeled (Ghirardi et al., 2006a,b).

In agreement with provisions of current European regulations on sheep and goat identification (ID) and registration (EC 21/2004; EC 1560/2007; EC 933/2008), RFID rumen boluses have been used in Spain since 2006 as electronic devices (Real Decreto 947/2005). Nevertheless, the retention rate of boluses in Spanish goat breeds is noticeably lower than in sheep, especially for dairy breeds (JRC, 2003; MAPA, 2007; Carné et al., 2009a). It has been suggested that feed management, as well as goat mature size and breed, affects bolus retention rates (MAPA, 2002; Capote et al., 2005; Carné et al., 2009a,c).

The objective of this study was to establish a regression model to estimate the retention rate of rumen boluses according to their physical features in goats. The model obtained could be used to enable the design of optimized boluses for different purposes (e.g., electronic ID, monitoring sensors, and supplement release) and to provide the expected retention rate of different bolus types commercially available under practical conditions in goats.

\section{MATERIALS AND METHODS}

Animal care conditions and management practices followed procedures stated by the Ethical Committee of Animal and Human Experimentation of the Universitat Autònoma de Barcelona, and the guidelines of the Spanish Committee on Animal Electronic Identification (MAPA, 2007).

\section{Animals and Management}

A total of 2,239 adult goats from 3 breeds (dairy purpose: Murciano-Granadina, $\mathrm{n}=1,326$; and French Alpine, $\mathrm{n}=381$; meat purpose: Blanca de Rasquera, $\mathrm{n}=532$ ) were used. The Murciano-Granadina goats belonged to 4 commercial dairy farms (Tona, Barcelona, $\mathrm{n}=274$; Sant Vicenç de Castellet, Barcelona, $\mathrm{n}=291 ;$ Juneda, Lleida, $\mathrm{n}=410$; and Terradelles, Girona, $\mathrm{n}=239$ ) and 1 experimental farm (S1GCE, Servei de Granges i Camps Experimentals, Universitat Autònoma de Barcelona, Bellaterra, Barcelona, $\mathrm{n}=$ 112) in Spain. The Murciano-Granadina goats from the commercial farms were managed to obtain 1 kidding per year under intensive conditions, being kept indoors and fed hay and concentrate. In the case of the S1GCE experimental farm, goats additionally grazed $5 \mathrm{~h}$ a day (1000 to $1500 \mathrm{~h}$ ) on cultivated Italian ryegrass pasture. In all cases, does were milked once daily in the morning (0700 to $1100 \mathrm{~h}$ ). The French Alpine goats belonged to
1 commercial dairy farm (Villarcayo, Burgos, Spain) managed similarly to the Murciano-Granadina commercial farms, although in this case does were milked twice daily (0630 and $1730 \mathrm{~h}$ ).

The Blanca de Rasquera goats, a local Catalan breed adapted to the harsh environment of the Mediterranean coastal mountains and intended for meat production (Carné et al., 2007), belonged to 1 commercial farm (Horta de Sant Joan, Tarragona, Spain) managed for an annual kidding rate of 1.5. The herd was managed in a semi-extensive production system, grazing $8 \mathrm{~h} / \mathrm{d}$ (1000 to $1800 \mathrm{~h}$ ) on Mediterranean macchia. Lactating does grazed on cultivated pastures and were supplemented with alfalfa hay and concentrate in the shelters.

All goats from the S1GCE experimental farm that died or were culled during the experiment were sent to the Pathology Service of the Universitat Autònoma de Barcelona for necropsy.

\section{Visual Ear Tags}

The Murciano-Granadina goats were individually identified with 2 types of official plastic ear tags: V1, double flag type (weight, $5.1 \mathrm{~g}$; flag piece dimensions, $37 \times 39$ mm; Rumitag, Esplugues de Llobregat, Barcelona, Spain), and V2, flag-button type (weight, 4.2 g; flag piece dimensions, $38 \times 40 \mathrm{~mm}$; Azasa-Allflex, Madrid, Spain). All goats born after July 2005 wore V1 in the right ear, according to current European regulations (EC 21/2004; EC 933/2008). For goats born before July 2005, V2 were applied in the right ear, in agreement with the former European and Spanish regulations on livestock ID (Directive 92/102/CEE; Real Decreto 205/1996), placing the button piece in the inner face of the ear.

The Blanca de Rasquera goats were visually identified with either V1 or V2 official ear tag types in a similar way to that detailed for the Murciano-Granadina goats. The French Alpine goats had been brought from different French farms and maintained their official ID consisting of 2 official flag-flag yellow plastic ear tags (41 × $48 \mathrm{~mm}$; Allflex, Vitré, France), according to current French legislation (Arrêté of June 26 2006).

\section{Rumen Boluses and Administration Procedures}

A total of 2,482 boluses belonging to 19 different prototypes and commercial devices and varying in their physical features [length, outside diameter (o.d.), weight $(\mathbf{W})$, volume $(\mathbf{V})$, and specific gravity (SG)] were used (Table 1). Administration of boluses with extremely different physical features was expected to result in a wide range of retention rate values, thereby 
Table 1. Features and retention rates of electronic rumen boluses for the permanent identification of goats

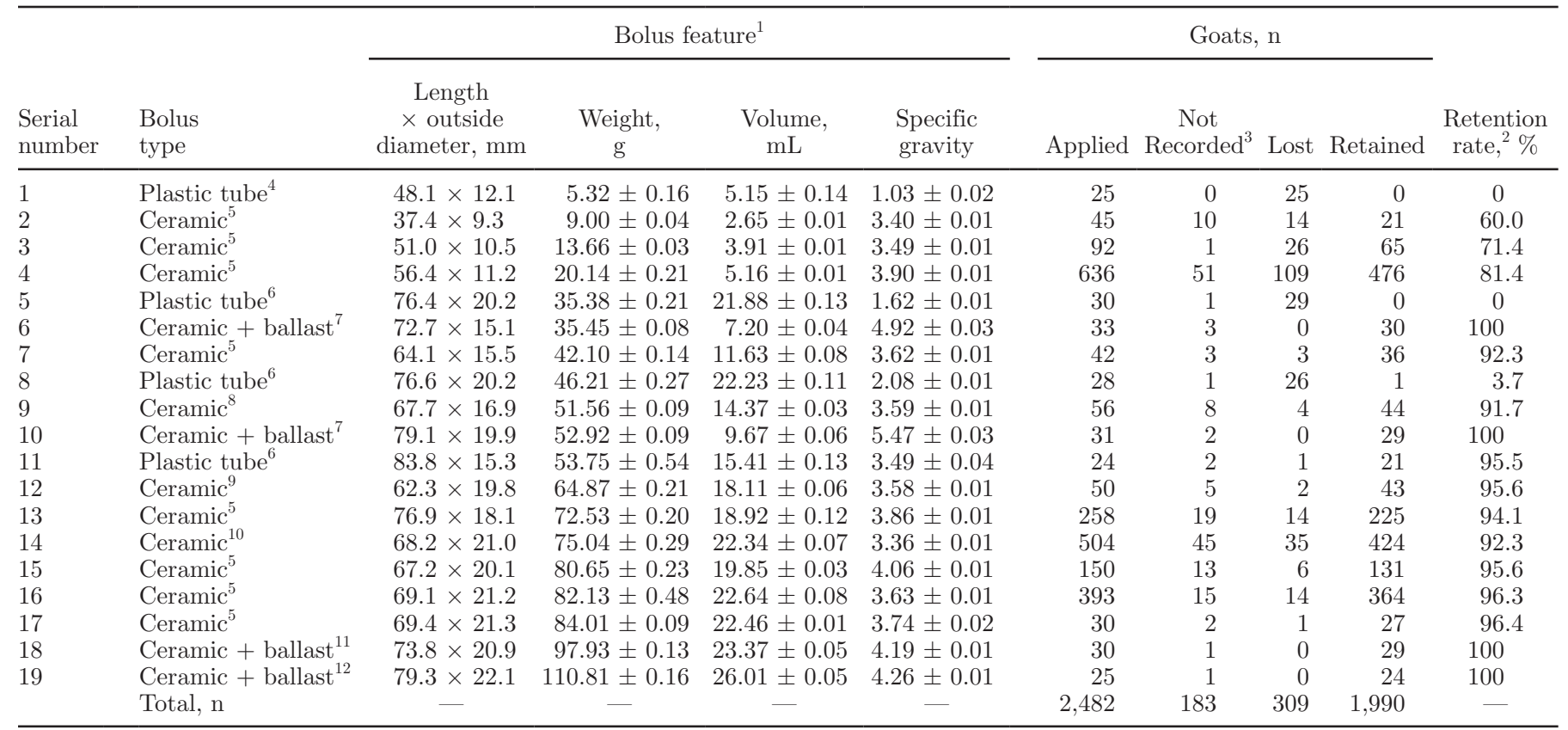

\footnotetext{
${ }^{1}$ Each bolus contained a half-duplex glass encapsulated transponder $(32 \times 3.8 \mathrm{~mm})$.

${ }^{2}$ Factual values.

${ }^{3}$ Animals that died or left the study before 1 yr after bolusing and were not included in the calculations.

${ }^{4}$ Hand-made prototype consisting of a plastic tube filled with silicone and sealed with epoxy resin.

${ }^{5}$ Prototypes made of silica, alumina, and zircon mixtures.

${ }^{6}$ Hand-made prototype consisting of a plastic tube containing a type 4 ceramic bolus, filled with silicone (type 5) or concrete (type 8) and sealed with epoxy resin.

${ }^{7}$ Hand-made prototype consisting of a type 4 ceramic bolus with a stainless steel ballast (type 6: $15.3 \mathrm{~g}$; type 10: $32.8 \mathrm{~g}$ ) attached.

${ }^{8}$ Standard commercial bolus (Innoceramics, Teramo, Italy).

${ }^{9}$ Standard commercial bolus (Allflex, Vitré, France).

${ }^{10}$ Standard commercial bolus (Rumitag, Esplugues de Llobregat, Spain).

${ }^{11}$ Hand-made prototype consisting of a type 15 bolus with a stainless steel ballast $(17.2 \mathrm{~g})$ attached, and a thermo-retractile plastic cover.

${ }^{12}$ Hand-made prototype consisting of a type 15 bolus with a stainless steel ballast $(30.5 \mathrm{~g})$ attached, and a thermo-retractile plastic cover.
}

allowing development of a regression model of bolus retention in the reticulorumen of goats according to bolus features.

Eleven bolus types were cylindrical devices made of nonporous, dense ceramic materials; 3 were commercial devices for ruminant electronic identification, and the remaining 8 were prototypes of different dimensions made of silica, alumina, and zircon mixtures, to obtain a range of SG (i.e., 3.40 to 4.06). Four more boluses consisted of cylindrical plastic tubes containing 1 small bolus and different filling materials (silicone, concrete, or metal ballasts). The remaining 4 bolus types consisted of ceramic prototypes with stainless steel ballasts attached to one end to increase the SG.

A random sample of 10 boluses of each type $(\mathrm{n}=$ 190) was collected to measure their physical features under laboratory conditions using a precision weigh- ing scale (accuracy, 0.01 g; BP 3100 P, Sartorius AG, Göttingen, Germany) and an electronic digital caliper (accuracy, $0.03 \mathrm{~mm}$; Shaodong Feiyue Hardware Tools Factory, Yiwu, China).

The SG (density rate of a given substance with respect to density of water at $1 \mathrm{~atm}$ of pressure and $4^{\circ} \mathrm{C}$ ) of each bolus was measured according to the Archimedes principle by contrasting the weight of the bolus with the weight of its volume of distilled water, similarly to the method described by Ghirardi et al. (2006a).

Each bolus contained a half-duplex glass encapsulated transponder of $32 \times 3.8 \mathrm{~mm}$ (Ri-Trp-RR2B-06, Tiris, Almelo, the Netherlands), which worked at a frequency of $134.2 \mathrm{kHz}$ in agreement with the current International Organization for Standardization (ISO) standards on animal electronic ID (ISO, 1996, 2009). In goats born after July 2005, transponder codes in- 
cluded the country (Spain, 0724), retagging counter (00), species (sheep and goat, 04), and a 12-digit serial number in which the autonomous community (Catalonia, 09) was included, according to the current Spanish (Real Decreto 947/2005) and European (EC 21/2004; $2006 / 968 / E C)$ regulations. For the rest of the goats, ISO transponders with the ICAR (2010) manufacturer codes (Allflex, 982; Innoceramics, 957; Rumitag, 964) and a 12-digit serial number were used.

All boluses were administered using balling guns adapted to each bolus type. Administration was done as described previously by Caja et al. (1999a) and Carné et al. (2009c).

To check for possible electronic failures during administration procedures, each bolus was read immediately before and after administration by using full-ISO radio frequency hand-held transceivers (Ges2S, Rumitag) able to read boluses at a minimum distance of $20 \mathrm{~cm}$, as specified in the European Regulation in this regard (EC 933/2008). For the postadministration readings, a directional caudo-cranial sweep in the abdomen region was performed with hand-held transceivers to ensure the proper descent of the bolus into the reticulorumen. Subsequently, bolus type and goat ID data (goat breed, and ear tag and farm codes) were typed and stored into the reader.

\section{Monitoring of Identification Devices}

Boluses were read in static conditions (animals restrained in the pen or in the milking parlor) with the hand-held reader at wk 1 and mo 1 after administration to register early losses, and thereafter every 2 mo until 12 to 18 mo depending on the administration date. From the overall 309 goats that lost the administered bolus prototypes, 243 were re-identified with an improved bolus design. Boluses that could not be monitored for at least $1 \mathrm{yr}$ of study were excluded from calculations because $1 \mathrm{yr}$ is the minimum period indicated by the International Committee for Animal Recording (ICAR) to carry out extended field tests on the use of livestock ID devices (ICAR, 2009). Additionally, performances of compulsory official ear tags in Murciano-Granadina $(\mathrm{V} 1, \mathrm{n}=168 ; \mathrm{V} 2, \mathrm{n}=502)$ and Blanca de Rasquera $(\mathrm{V} 1, \mathrm{n}=218 ; \mathrm{V} 2, \mathrm{n}=276)$ goats were registered at 1 yr for comparison. Lost ear tags of French Alpine goats were directly managed by the technical staff of the farm and no data on retention rate throughout the study was available.

The retention of ID devices was expressed as follows: retention rate $(\%)=$ (no. of retained devices/no. of monitored devices) $\times 100$.

Unreadable boluses were deemed as lost. Additionally, one dynamic reading control was carried out in different groups of animals belonging to 3 farms of Murciano-Granadina goats $(\mathrm{n}=873)$, as well as in the French Alpine $(\mathrm{n}=274)$ and Blanca de Rasquera ( $\mathrm{n}$ = 349) goat farms, totaling 1,496 bolus readings. A portable runway (width, $40 \mathrm{~cm}$; length, 200 to $300 \mathrm{~cm}$ ) with a left-side-installed frame antenna $(94 \times 52 \mathrm{~cm}$; Rumitag) in vertical position, and connected to a stationary transceiver F-210 (Rumitag) was used. Goats passed in front of the frame antenna at an approximate speed of 2 goats/s. A minimum reading distance in static conditions of $50 \mathrm{~cm}$, as laid down in the European regulation in this regard (EC 933/2008), was checked before goats passed through the runway. A hand-held transceiver (Ges2S, Rumitag) was used to confirm bolus readability in static conditions (bolus retention) whenever an unread bolus was detected. The reading efficiency under dynamic conditions was calculated as follows: dynamic reading efficiency $(\%)=($ no. of read devices/no. of readable devices) $\times 100$.

\section{Statistical Analyses}

Bolus retention data were analyzed with a nonlinear least squares regression model, using the NLIN procedure of SAS v.9.1 (SAS Inst. Inc., Cary, NC) and assuming a logistic distribution, as previously carried out in cattle and sheep (Ghirardi et al., 2006a,b). Because no farm effect on bolus retention could be detected for any bolus type, this factor was not included in the model. The final model included the $\mathrm{W}$ and $\mathrm{V}$ of boluses as independent covariates:

$$
y=\frac{\mathrm{A}}{1+b_{0} \cdot e^{-\left(b_{1} \cdot \mathrm{W}+b_{2} \cdot \mathrm{V}\right)}},
$$

where $y=$ the bolus retention rate (response variable); $b_{0}, b_{1}$, and $b_{2}=$ regression coefficients; and $\mathrm{A}=$ the maximum value of bolus retention rate expressed as a percentage $(\mathrm{A}=100)$. The WEIGHT statement of SAS was used to allow for a weighted regression according to the number of boluses of each type evaluated.

Retention rate of ear tags was analyzed with the CATMOD procedure of SAS, and a Logit model with an estimation method of maximum likelihood (Cox, 1970) was used. Effects evaluated were breed (MurcianoGranadina and Blanca de Rasquera) and ear tag type (V1 and V2). The CATMOD procedure was also used to analyze the bolus dynamic reading efficiency, evaluating the effects of bolus type, goat breed, and herd. Inverse rearrangement of the retention rate model for $y$ $=99.95 \%$ was used for estimating the critical values of bolus dimensions. Approximate standard errors of the estimates were calculated by partial derivation using the Delta method (Raykov and Marcoulides, 2004). 
In all cases, significance was declared at $P<0.05$, and variables that were not significant $(P>0.20)$ were removed from the final models.

\section{RESULTS AND DISCUSSION}

\section{Features of Boluses, and Administration and Reading Performances}

Features of each bolus type are detailed in Table 1. For practical purposes, boluses used in this study were divided into 3 categories according to V: small (2.7 to $7.2 \mathrm{~mL}$ ), medium-sized (9.7 to $15.4 \mathrm{~mL}$ ), and standardsized and large (18.1 to $26.0 \mathrm{~mL}$ ). With regard to their dimensions, boluses ranged from 37.4 to $83.8 \mathrm{~mm}$ in length, and from 9.3 to $22.1 \mathrm{~mm}$ in o.d. Boluses also varied in $\mathrm{W}$, ranging from 5.3 to $110.8 \mathrm{~g}$, as well as SG, ranging from 1.0 to 5.5. Prototypes with attached stainless steel ballasts were not cylindrical, as the ballast was a ball and had a larger o.d. than the body of the bolus. A total of 7 bolus types in our study (\#2, 3, 4, 9, 12, 14 and 15; Table 1) have already been tested in fattening lambs and adult sheep (Teyssier et al., 2003; Garín et al., 2005; Ghirardi et al., 2006b, 2007), and in goats (Carné et al., 2009a,c).

No incidences at bolus administration were reported for any of the bolus types. Moreover, a large bolus prototype $(\# 19,26 \mathrm{~mL})$, which had never been tested in small ruminants, was easily and safely administered to goats in our experiment. These findings confirm earlier results in sheep and goats in which 22-mL boluses were safely administered by trained operators to adult sheep and goats (Caja et al., 1999a; Ghirardi et al., 2006a; Carné et al., 2009c) as well as to replacement sheep and goats with BW greater than 30 and $25 \mathrm{~kg}$, respectively (Caja et al., 1999a; Carné et al., 2009a). No casualties registered during the study appeared to be related to bolus administration or their long-term location in the reticulorumen; moreover, no necropsy reports of dead goats from the experimental farm indicated any damage caused by the bolus, and in all cases, the bolus was properly located in the reticulorumen.

Retained boluses could easily be read in static conditions in the shelters and the milking parlor by using hand-held readers (static reading efficiency, 100\%), except for the prototypes with metal ballasts (static reading efficiency, 93.3\%). In the latter case, several reading attempts with the hand-held reader were frequently necessary, probably because of interference in the signal emitted by the transponder. In fact, proper retention of 8 of these ballasted boluses had to be confirmed at the end of the study by using portable x-ray equipment (model X803G, MinXray Inc., Northbrook, IL).
Fallon (2001) described large RFID boluses made of plastic with steel ballasts attached to one end; these ballasts increased the SG and allowed swift submersion through the rumen contents. Nevertheless, the body of the bolus encased larger transponders to compensate for poor reading performance because of interference caused by the metal ballast. The use of this sort of device, with SG up to 2.75, has been described in sheep (Caja et al., 1996) and cattle (Lambooij et al., 1999; Fallon et al., 2002).

With respect to dynamic reading efficiency performed in a runway, goats identified with metal-ballasted boluses were excluded to avoid misreading, as the electric conductivity of metal may interfere with radiofrequency electromagnetic fields and dramatically reduce the reading distance achieved. This measure was taken irrespective of the bolus being readable or not in static conditions. At the end of the study, 8 reading failures of nonballasted boluses were registered, thereby obtaining a reading efficiency under dynamic conditions of $99.5 \%$. Moreover, no differences according to bolus type, goat breed, or herd could be established. Carné et al. (2010) reported bolus dynamic reading efficiency of $95.2 \%$ in the same goat breed, using similar HDX transponders and a lateral antenna, but under an electronic collision environment. Readabilities greater than $99.5 \%$ were described by using both mini ( 3 to $5 \mathrm{~mL}$ ) and standard-sized $(22 \mathrm{~mL})$ boluses in different meat and dairy sheep breeds (Ghirardi et al., 2006b); no bolus or herd effect was detected in this case. Moreover, Stewart et al. (2007) and Wallace et al. (2008) showed 93.8 to $99.9 \%$ dynamic reading efficiency of electronic ear tags, according to RFID technology and transceiver type used in cattle.

\section{Bolus Retention and Regression Model}

Retention of the different bolus types is shown in Table 1. Retention rates ranged from 0 to $100 \%(P<$ 0.001 ) as anticipated according to the variety of bolus features, and previous research in sheep and cattle (Ghirardi et al., 2006a,b). The lowest retention rates $(<3.8 \%)$ were obtained for the bolus types \#1, 5 and 8, which varied in W (5.3 to $46.2 \mathrm{~g}$ ) and V (5.2 to 22.2 $\mathrm{mL}$ ), showing $\mathrm{SG}<2.1$. On the contrary, the greatest retention rate values $(100 \%)$ were observed with bolus types \#6, 10, 18, and 19, which corresponded to a wide range of $\mathrm{W}$ (35.5 to $110.8 \mathrm{~g}$ ) and $\mathrm{V}$ (7.2 to $26.0 \mathrm{~mL}$ ), although in these cases $\mathrm{SG}>4.1$. Thus, $\mathrm{SG}$ appeared to be of major relevance for bolus performance according to retention results. Only the last 4 bolus types, where no losses occurred, were above the ICAR reten- 


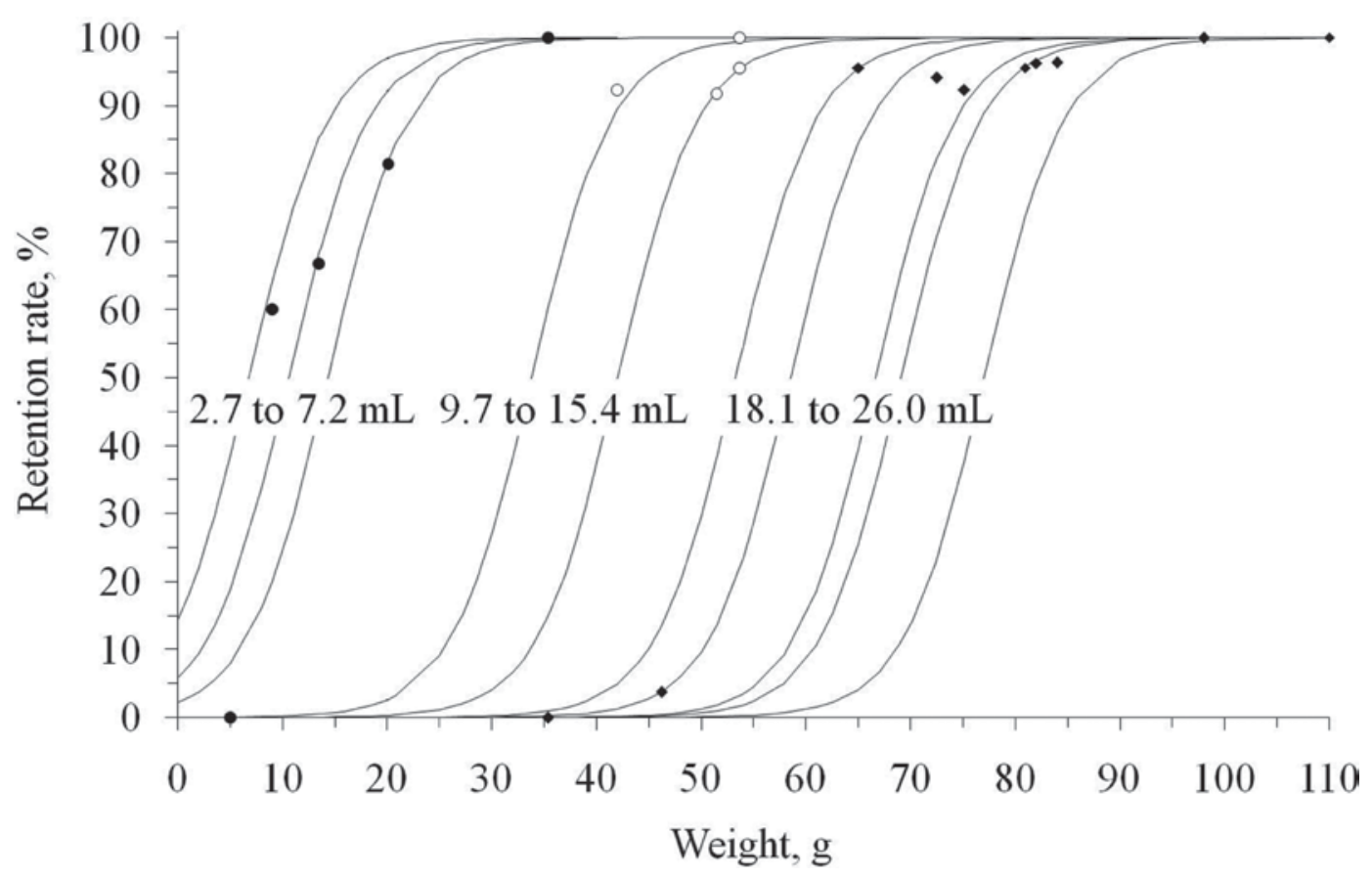

Figure 1. Bolus retention rates $(\%)$ according to their weight $(\mathrm{W}, \mathrm{g})$ and volume $(\mathrm{V}, \mathrm{mL})$ in goats under on-farm conditions $(\bullet=$ small boluses: 2.7 to $7.2 \mathrm{~mL}$; $\bigcirc=$ medium-sized boluses: 9.7 to $15.4 \mathrm{~mL}$; $=$ standard-sized and large boluses: 18.1 to $26.0 \mathrm{~mL}$ ). Lines are the estimated retention rates for different bolus volumes according to the logistic regression as follows: Retention rate $(\%)=\frac{100}{1+0.734 \cdot e^{-(0.261 \cdot \mathrm{W}-0.787 \cdot \mathrm{V})}}$.

tion requirement for animal ID (>98\% at 1 yr after administration; ICAR, 2009).

At the end of the study, 2,299 boluses (92.6\%) had been monitored for at least $1 \mathrm{yr}$, which corresponded to $1,398(60.8 \%)$ Murciano-Granadina, 394 (17.1\%) French Alpine, and 507 (22.1\%) Blanca de Rasquera goats; these boluses made up the data set utilized to assess the regression model.

Different dimensions (W, V, SG, length, and o.d.) were evaluated to properly estimate bolus retention rate according to their physical features. Among the different models tested, the logistic model taking the $\mathrm{W}$ and $\mathrm{V}$ of boluses as covariates offered the greatest coefficient of determination between estimated and observed retention rates of each bolus type shown in Table $1\left(\mathrm{R}^{2}=0.98 ; P<0.001\right)$, as previously indicated by using analogous models for sheep and beef cattle (Ghirardi et al., 2006a,b). It bears mentioning that when considering $\mathrm{W}$ and $\mathrm{V}, \mathrm{SG}$ (equal to $\mathrm{W} / \mathrm{V}$ ) was implicitly considered as well.

Values $\pm \mathrm{SE}$ of the estimated parameters of the model were $b_{0}=0.734 \pm 0.089, b_{1}=0.261 \pm 0.037$, and $b_{2}=-0.787 \pm 0.122$. The equation of the model estimating the percentage of bolus retention rate in goats according to bolus weight and volume was

$$
\text { Retention rate }(\%)=\frac{100}{1+0.734 \cdot e^{-(0.261 \cdot \mathrm{W}-0.787 \cdot \mathrm{V})}} \cdot[1]
$$

Factual retention data and estimated retention curves according to the different bolus volumes are shown in Figure 1. For any given bolus $\mathrm{V}$, retention rate increased when W and SG increased. In contrast, increasing the bolus W while maintaining the SG offered only a moderate improvement of the retention rate. We also confirmed that suitable retention of small boluses is feasible if they are appropriately designed. As previously indicated in sheep and cattle, a reduction in bolus $\mathrm{V}$ not affecting the retention performance can be accomplished by increasing the SG (Garín et al., 2005; Ghirardi et al., 2006a,b).

Error of the estimated retention averaged 2.4 percentage units (Figure 2), which was greater than that reported in sheep (1.3) and cattle (1.5) by Ghirardi et al. (2006a,b). Greater error in our study may be explained by the larger number of boluses tested and the fewer bolus types with a $100 \%$ retention rate with respect to the aforementioned studies. In addition, and unlike other goat breeds, some Spanish dairy breeds have shown great variability in bolus retention rates 


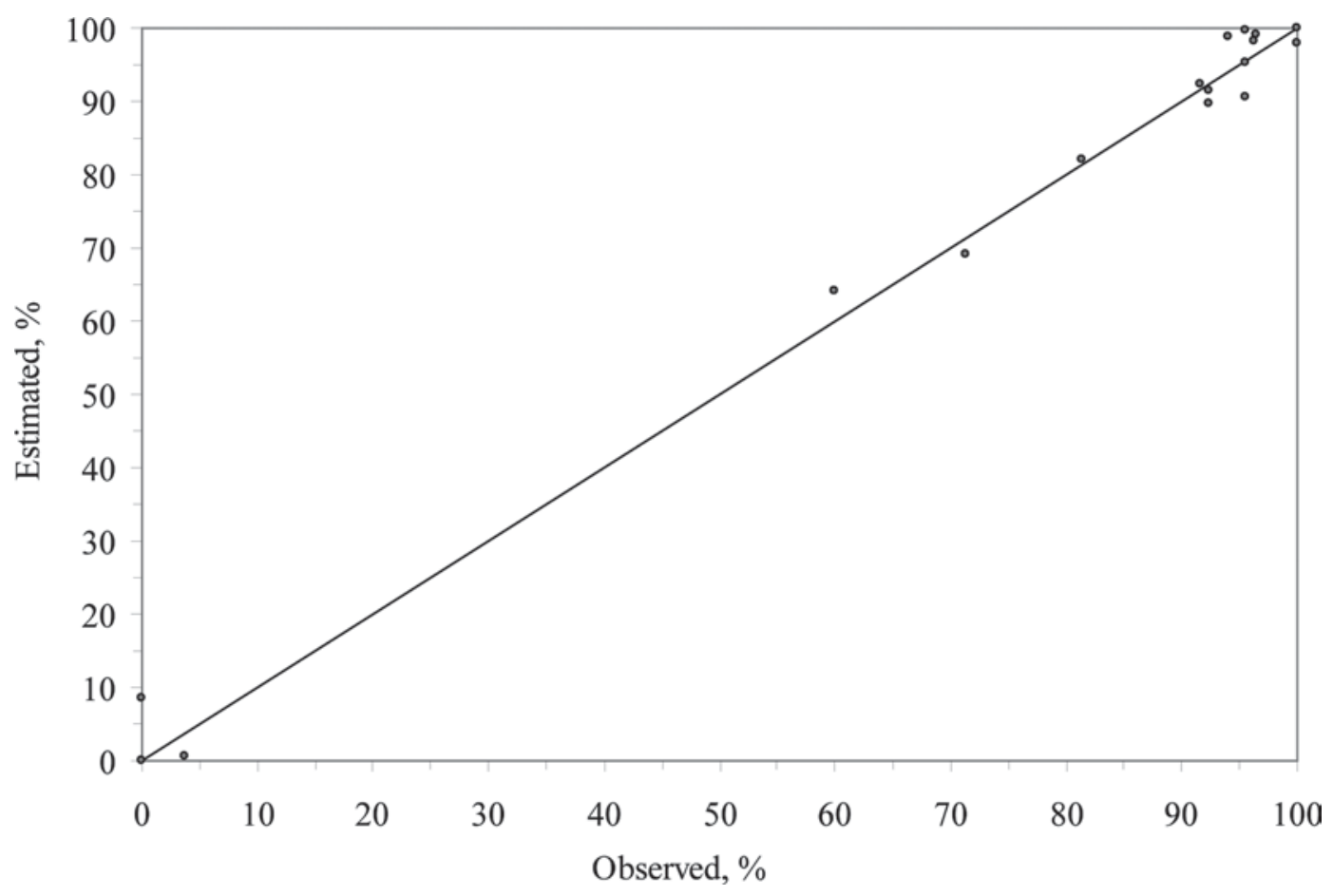

Figure 2. Comparison of observed and estimated values of bolus retention rate in goats $(\mathrm{SEM}=2.4)$.

(MAPA, 2002, 2007; Carné et al., 2009a). In fact, it has been suggested that breed and management conditions (i.e., feeding conditions) may affect bolus retention in goats (JRC, 2003; Capote et al., 2005; Carné et al., 2009a,c).

Taking this variability into account, the construction of the model was aimed at obtaining devices with optimum retention rates irrespective of breed and management, rather than estimating the most representative mean retention in the goat species. For this reason, more than $60 \%$ of boluses included in the model belonged to Murciano-Granadina Spanish dairy goat, which has been indicated to show the widest range of retention values, generally being poorer than in other breeds evaluated (MAPA, 2002, 2007; Capote et al., 2005; Pinna et al., 2006). Concentrate-based and small particle sized total mixed rations commonly used in Murciano-Granadina goats have been suggested to affect bolus retention (Carné et al., 2009a).

Available literature referring to medium- and longterm ( $>8 \mathrm{mo}$ ) bolus retention in goats was added to the model (Caja et al., 1999a; JRC, 2003; Capote et al., 2005; San Miguel et al., 2005; Pinna et al., 2006; MAPA, 2007; Carné et al., 2009a,b) as previously done by Ghirardi et al. (2006b) in sheep. The regression coefficients obtained in our meta-analysis were as follows: $b_{0}=0.832, b_{1}=0.255$, and $b_{2}=-0.715$. Nevertheless, the model constructed with our collected data tended to be more conservative than that obtained in the meta-analysis. Thus, estimation curves with our data were displaced to the right (Figure 1), indicating that greater $\mathrm{W}$ and $\mathrm{SG}$ are required to reach the desired bolus retention. Hereafter, to facilitate the presentation of results and their subsequent discussion, reference will be made to volumes of 5,15 , and $22 \mathrm{~mL}$, which were chosen as representative of commercially available mini-, medium-, and standard-sized boluses, respectively. In this sense, curve displacement to the right in our produced model was more noticeable than in the meta-analysis when dealing with large bolus volumes. Thus, averaged differences of estimated retentions, including the literature references (meta-analysis) or only using our collected data, were 1.7, 4.3 , and $6.3 \%$ for 5-, 15-, and 22-mL volumes, respectively. Nevertheless, when focusing on the critical retention $>98 \%$ indicated by ICAR (2009), these differences were reduced to 0 , 0.3 , and $0.6 \%$ for the same $\mathrm{V}$ considered. In view of the low variability between the 2 models for retention rates close to $100 \%$, and the more strict requirements of our data to design boluses with optimum retention, we concluded that the model obtained with our observed data was more suitable for the purpose of this work.

In the present study, taking into consideration the unfavorable scenario of bolus losses previously reported in goats, we decided to evaluate results for a retention rate of $99.95 \%$, thereby being even more stringent with bolus requirements than in previous models published in cattle (Ghirardi et al., 2006a) and sheep (Ghirardi et 
al., 2006b). Hence, the previous equation [1] was rearranged for $99.95 \%$ retention rate and 3 new equations were obtained, which allowed the assessment of the estimated weight $(\widehat{W})$, estimated volume $(\widehat{\mathrm{V}})$, and estimated SG $(\widehat{\mathrm{SG}})$ of boluses for their optimum retention in goats:

$$
\begin{gathered}
\widehat{\mathrm{W}}=27.83+3.01 \cdot \mathrm{V}, \\
\widehat{\mathrm{V}}=\mathrm{W} / 3.01-9.25, \\
\widehat{\mathrm{SG}}=27.83 / \mathrm{V}+3.01 .
\end{gathered}
$$

According to equations [2] and [4], the critical values of $\widehat{\mathrm{W}}$ and $\widehat{\mathrm{SG}}$ and approximate standard errors for obtaining the desired $99.95 \%$ retention rate for the medium $(15 \mathrm{~mL})$ and standard sized $(22 \mathrm{~mL})$ boluses, were $73.1 \pm 22.4 \mathrm{~g}(\widehat{\mathrm{SG}}=4.87)$ and $94.2 \pm 21.3 \mathrm{~g}(\widehat{\mathrm{SG}}=$ $4.28)$, respectively. The larger estimated standard error $(>29.9)$ and $\widehat{\mathrm{SG}}(>8.5)$ obtained in the case of miniboluses $(5 \mathrm{~mL})$ advised against their use in goats.

Before comparing our results with those obtained in the sheep and beef cattle models (Ghirardi et al., $2006 \mathrm{a}, \mathrm{b}$ ), it should be pointed out that V and W coefficients in the published equation of the sheep model (Ghirardi et al., 2006b) were interchanged. Corrected exponent in the equation of sheep model of Ghirardi et al. (2006b) was $-0.504 \cdot \mathrm{W}+0.763 \cdot \mathrm{V}$, from which we calculated $(99.95 \%$ retention rate) that $\mathrm{W}=15.34+$ $1.51 \cdot \mathrm{V}$. For an estimated retention rate of $99.95 \%$, the minimum bolus $\mathrm{W}$ and $\mathrm{SG}$ in sheep were $22.9 \mathrm{~g}$ ( $\mathrm{SG}=$ $4.57)$ for 5 -mL boluses, $38.0 \mathrm{~g}(\mathrm{SG}=2.53)$ for $15-\mathrm{mL}$ boluses, and $48.6 \mathrm{~g}(\mathrm{SG}=2.20)$ for $22-\mathrm{mL}$ boluses. In the case of cattle, estimated weight and SG for the 99.95\% retention rate and $\mathrm{V}$ derived from the model of Ghirardi et al. (2006a) were $58.1 \mathrm{~g}$ (SG 11.6), $74.8 \mathrm{~g}$ (SG 4.99), and $86.5 \mathrm{~g}$ (SG 3.93), respectively.

It is remarkable that coefficient values in goats were approximately double those in sheep, which makes evident the differences between species regarding retention performance of boluses. On the contrary, differences between goats and cattle were much lower, although they varied considerably depending on the dimensions of the bolus. No studies referring to interspecies differences in the regurgitation of foreign bodies located in the reticulorumen have been published, which is a key point for the retention of monitoring sensors (e.g., temperature, $\mathrm{pH}$ ) and slow-release devices (e.g., supplements, antihelminthic, antifoaming agents).
Figure 3 summarizes the results obtained in our study, showing the variety of combinations of $\mathrm{W}, \mathrm{V}$, and SG that would allow production of boluses with an optimum retention rate $(99.95 \%)$ in goats. To design boluses for optimal retention and also allowing the administration at early ages, the use of high density boluses with reduced $\mathrm{V}$ is required, in agreement with Caja et al. (1999a), Fallon (2001), and Ghirardi et al. $(2006 a, b)$. As radiofrequency-translucent materials are necessary for RFID, dense ceramic materials are being used at present for this purpose, and boluses with SG up to 4.1 have been produced. Yet, estimated SG for mini-boluses (e.g., $5 \mathrm{~mL}$ volume) to be retained in goats is greater than 8.5. Therefore, as long as currently utilized materials do not allow such high SG values to be reached, the use of mini-boluses for goat ID should be discarded. Unsuitability of mini-boluses for goat ID was noted in earlier reports (Carné et al., 2009a,c); this is a major difference between sheep and goats because mini-boluses with $\mathrm{SG}>3.5$, and $\mathrm{W}>15 \mathrm{~g}$, have been successfully used (retention $>98 \%$; ICAR, 2009) for permanent sheep ID (Teyssier et al., 2003; Ghirardi et al., 2006b, 2007; MAPA, 2007).

Results of the present work indicated the need for a SG between 4.9 and 5.8 to produce medium-sized boluses (e.g., 10 to $15 \mathrm{~mL}$ of volume) that can be properly retained in goats; currently available radio-translucent materials could be successfully used to obtain boluses with such required physical features.

\section{Ear Tag Retention}

Performance of visual ear tags is shown in Table 2. Damage by biting and breaking of the flag pieces was greater $(P<0.05)$ in V2 than in V1 ear tags, and a breed effect was observed in V2. Most damages registered in this latter ear tag type were due to the breakage of the flag piece, thus resulting in button-like ear tags; the breakage of flag pieces in V2 seemed to be caused by a too-weak insertion of the flag piece to the ear tag body. As only lost devices were replaced by veterinary officials during the annual blood sampling campaigns (Carné et al., 2010), the yearly incidence of such breakages was not established. These findings may be of relevance for $\mathrm{V} 2$ retention as button-button RFID ear tags have been indicated to offer greater long-term retention rates than flag types (Carné et al., 2009a). Ear tag retention rate varied between herds (92.2 to $98.0 \%)$, although only a tendency of difference $(P=$ 0.08 ) was detected between herds for V2 tags. Retention of V2 was numerically greater than V1 in the 2 goat breeds evaluated, although only the retention of V1 in Blanca de Rasquera and V2 in Murciano-Granadina goats differed (92.2 vs. $96.8 \%$, respectively; $P<0.05$ ). 


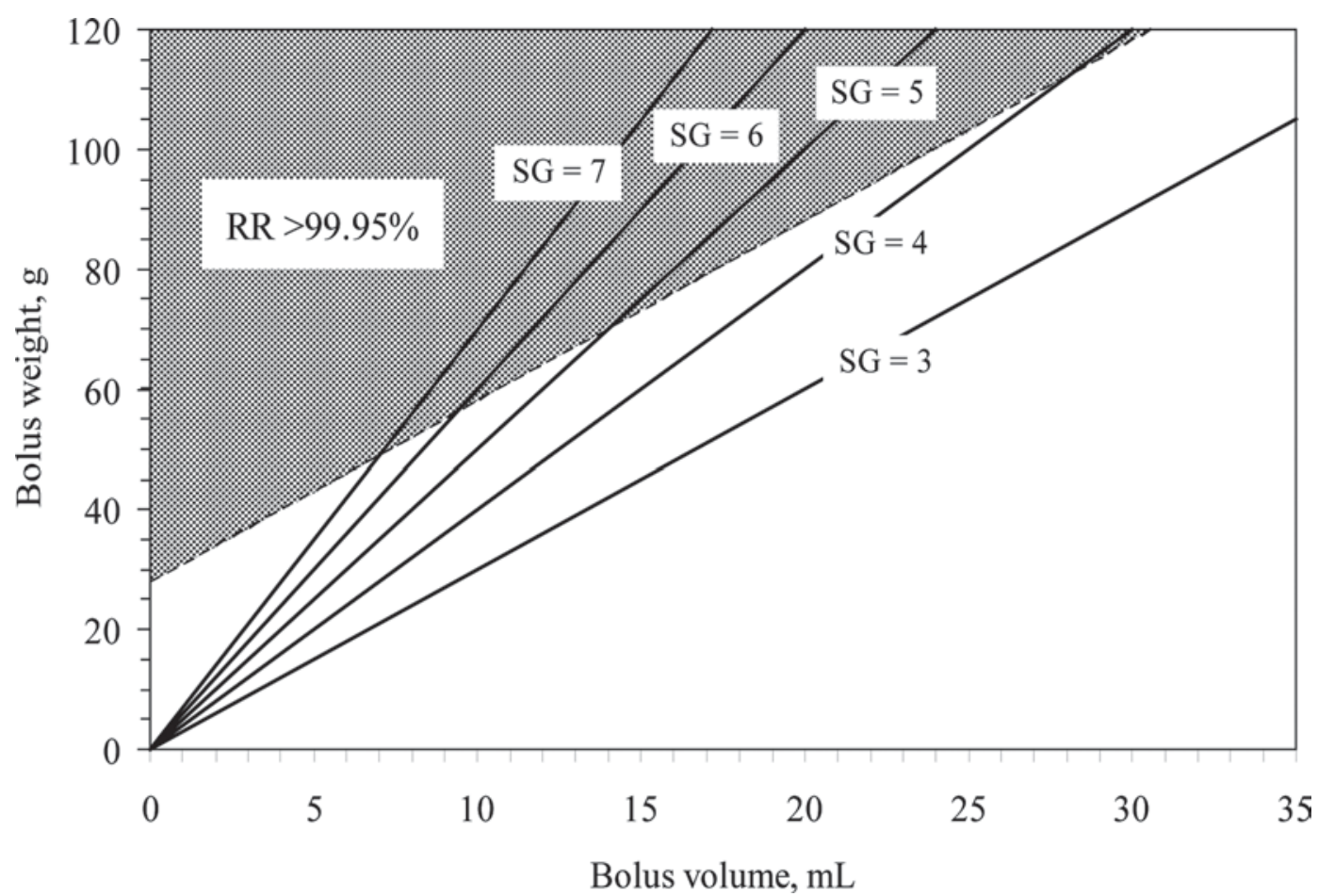

Figure 3. Bolus weight and volume combinations that allow a retention rate (RR) greater than 99.95\% (gray zone) according to bolus specific gravity (SG) in goats under on-farm conditions.

Despite the fact that literature in this regard is limited, losses in our study remained within the wide range of 1.4 to $17.1 \%$ reported in different goat breeds (Carné et al., 2009a,b). However, visual plastic ear tag retention values in our results did not meet the ICAR recommendations (>98\%) for official animal ID (ICAR, 2009).

\section{CONCLUSIONS}

A logistic model was obtained to estimate the bolus retention rate in goats. The model showed that the features of boluses markedly affect their retention in the reticulorumen of goats. Moreover, goat boluses need to be heavier and with greater specific gravity compared with those used in sheep and cattle to reach the retention rate required for official use ( $>98 \%)$. Mini-boluses similar to those used in sheep are not recommended in goats. On the other hand, medium-size boluses (10 to $15 \mathrm{~mL}$ ) with $\mathrm{SG}$ of 4.9 to 5.8 could be successfully produced with radio-translucent materials for their efficient retention in the reticulorumen of goats, thereby solving the current problem of using proper boluses for goat identification.

Table 2. Performance of visual plastic ear tags in Murciano-Granadina (dairy) and Blanca de Rasquera (meat) goat breeds at 1 yr of study ${ }^{1}$

\begin{tabular}{|c|c|c|c|c|c|c|}
\hline \multirow[b]{2}{*}{ Item } & \multicolumn{2}{|c|}{ Murciano-Granadina } & \multicolumn{2}{|c|}{ Blanca de Rasquera } & \multicolumn{2}{|c|}{ Overall } \\
\hline & V1 & $\mathrm{V} 2$ & $\mathrm{~V} 1$ & $\mathrm{~V} 2$ & V1 & $\mathrm{V} 2$ \\
\hline Ear tags, n & 168 & 502 & 218 & 276 & 386 & 778 \\
\hline Damaged, ${ }^{2} \%$ & $3.0^{\mathrm{a}}$ & $13.7^{\mathrm{b}}$ & $4.1^{\mathrm{a}}$ & $21.7^{\mathrm{c}, \mathrm{x}}$ & $3.6^{\mathrm{a}}$ & $16.6^{\mathrm{bc}, \mathrm{y}}$ \\
\hline Lost, $\%$ & 4.8 & 3.2 & 7.8 & 4.7 & 6.5 & 3.7 \\
\hline Retention rate, \% & $95.2^{\mathrm{ab}}$ & $96.8^{\mathrm{b}}$ & $92.2^{\mathrm{a}}$ & $95.3^{\mathrm{ab}}$ & $93.5^{\mathrm{a}}$ & $96.3^{\mathrm{b}}$ \\
\hline
\end{tabular}

\footnotetext{
${ }^{\mathrm{a}-\mathrm{c}}$ Within a row, values with different superscripts differ $(P<0.05)$.

${ }^{\mathrm{x}, \mathrm{y}}$ Within a row, values with different superscripts tended to differ $(P<0.1)$.

${ }^{1} \mathrm{~V} 1=$ double flag type, $5.1 \mathrm{~g}, 37 \times 39 \mathrm{~mm}$ flag dimensions (Rumitag, Esplugues de Llobregat, Spain); V2= flag-button type, $4.2 \mathrm{~g}, 38 \times 40 \mathrm{~mm}$ flag dimensions with the button piece placed on the inner side of the ear (Azasa-Allflex, Madrid, Spain).

${ }^{2}$ Ear tags with apparent signs of damage caused by biting or breakage of the flag pieces.
} 


\section{ACKNOWLEDGMENTS}

This work is part of a research project funded by the Spanish Ministry of Education (Plan Nacional I+D+i; Project AGL-2007-64541). The authors are grateful to the goatherds Salvador and Pepito Miralles (Horta de Sant Joan, Tarragona), José-Luís Casanueva (Sant Vicenç de Castellet, Barcelona), Llorenç and Martí Huguet (Terradelles, Girona), Gerard Porta (Juneda, Lleida), Lluís Mauri (Tona, Barcelona), and Alfonso Andújar and Victor Maeso (Villarcayo, Burgos) for taking part in this Spanish project; to Ramon Costa and the team of the Servei de Granges i Camps Experimentals of the Universitat Autònoma de Barcelona (Bellaterra, Barcelona, Spain) for the technical assistance and care of the animals; to Joan F. Vilaseca (Rumitag, Esplugues de Llobregat, Barcelona, Spain) for supplying part of the boluses; to Pere Puig and Joaquim Casellas (Universitat Autònoma de Barcelona, Spain) for statistical support; and to Nic Aldam (Barcelona, Spain) for the English revision of the manuscript.

\section{REFERENCES}

Abecia, J. A., and J. Torras. 2009. Aplicación de la pulsera electrónica Patuflex: Identificación de corderas y cabritas de reposición. Albéitar 129:54-55.

Ait-Saidi, A., G. Caja, S. Carné, A. A. K. Salama, and J. J. Ghirardi. 2008. Comparison of manual vs. semi-automatic milk recording systems in dairy goats. J. Dairy Sci. 91:1438-1442.

Caja, G., F. Barillet, R. Nehring, C. Marie, O. Ribó, E. Ricard, G. Lagriffoul, C. Conill, M. R. Aurel, and M. Jacquin. 1996. Comparison of different devices for electronic identification in dairy sheep. Pages 349-353 in Performance Recording of Animals. J. Renaud and J. van Gelder, ed. EAAP Pub. No. 87. Wageningen Pers, Wageningen, the Netherlands.

Caja, G., C. Conill, R. Nehring, and O. Ribó. 1999a. Development of a ceramic bolus for the permanent electronic identification of sheep, goat and cattle. Comput. Electron. Agric. 24:45-63.

Caja, G., S. Peris, C. Conill, R. Nehring, R. Roca, O. Ribó, and M. J. Milán. 1999b. Implementation of a system based on electronic identification for the official milk recording of dairy goats in Catalonia. Pages 406-411 in Milking and Milk Production of Dairy Sheep and Goats. F. Barillet and N. P. Zervas, ed. EAAP Pub. No. 95. Wageningen Pers, Wageningen, the Netherlands.

Capote, J., D. Martín, N. Castro, E. Muñoz, J. Lozano, S. Carné, J. J. Ghirardi, and G. Caja. 2005. Retención de bolos ruminales para identificación electrónica en distintas razas de cabras españolas. ITEA Prod. Animal 26(vol. extra):297-299.

Carné, S., G. Caja, M. A. Rojas-Olivares, and A. A. K. Salama. 2009b. Leg bands and rumen boluses for the long-term electronic identification of goats. J. Anim. Sci. 87(E-Suppl. 2):310. (Abstr.)

Carné, S., G. Caja, M. A. Rojas-Olivares, and A. A. K. Salama. 2010. Readability of visual and electronic leg tags versus rumen boluses and electronic ear tags for the permanent identification of dairy goats. J. Dairy Sci. 93:5157-5166.

Carné, S., G. Caja, A. A. K. Salama, and J. J. Ghirardi. 2009a. Longterm performance of visual and electronic identification devices in dairy goats. J. Dairy Sci. 92:1500-1511.

Carné, S., T. A. Gipson, M. Rovai, R. C. Merkel, and G. Caja. 2009c. Extended field test on the use of visual ear tags and electronic boluses for the identification of different goat breeds in the United States. J. Anim. Sci. 87:2419-2427.
Carné, S., N. Roig, and J. Jordana. 2007. La cabra Blanca de Rasquera: Caracterización estructural de las explotaciones. Arch. Zootecn. 56:43-54.

Cox, D. R. 1970. The Analysis of Binary Data. Chapman \& Hall, London, UK.

Fallon, R. J. 2001. The development and use of electronic ruminal boluses as a vehicle for bovine identification. Rev. Sci. Tech. Off. Int. Epizoot. 20:480-490.

Fallon, R. J., P. A. M. Rogers, and B. Earley. 2002. Project Report ARMIS No. 4623. Electronic Animal Identification. Beef Production Series No. 46. Grange Research Centre, Dunsany, Co. Meath, Ireland.

Fonseca, P. D., C. R. Roquete, J. L. Castro, A. G. Condeço, and J. V. Fernandes. 1994. Evaluation of migration, losses and breakages on electronic identification transponders implanted in four different sites in adult goats. Electronic identification of farm animals using implantable transponders. European Union General Directorate VI-FEOGA, Research Project, Final Report Vol. II, Exp. UE-03/2.2. European Commission, Brussels, Belgium.

Garín. D., G. Caja, and C. Conill. 2005. Performance and effects of small ruminal boluses for electronic identification of young lambs. Livest. Prod. Sci. 92:47-58.

Ghirardi, J. J., G. Caja, C. Flores, D. Garín, M. Hernández-Jover, and F. Bocquier. 2007. Suitability of electronic mini-boluses for the early identification of lambs. J. Anim. Sci. 85:248-257.

Ghirardi, J. J., G. Caja, D. Garín, J. Casellas, and M. HernándezJover. 2006a. Evaluation of the retention of electronic identification boluses in the forestomachs of cattle. J. Anim. Sci. 84:22602268 .

Ghirardi, J. J., G. Caja, D. Garín, M. Hernández-Jover, O. Ribó, and J. Casellas. 2006b. Retention of different sizes of electronic identification boluses in the forestomachs of sheep. J. Anim. Sci. 84:2865-2872.

Hasker, P. J. S., and J. Bassingthwaighte. 1996. Evaluation of electronic identification transponders implanted in the rumen of cattle. Aust. J. Exp. Agric. 36:19-22.

ICAR (International Committee for Animal Recording). 2009. International Agreement of Recording Practices. Guidelines approved by the General Assembly held in Niagara Falls, USA, June 2008. International Committee for Animal Recording, Rome, Italy.

ICAR (International Committee for Animal Recording). 2010. Animal Identification: List of manufacturer codes. Accessed May 11, 2009. http://www.service-icar.com/manufacturer_codes/Manufacturers _DB/manufacturer_codes_main.asp.

ISO. 1996. Agricultural Equipment. Radio-frequency Identification of Animals-Technical Concept. ISO 11785:1996 (E). 1st ed. International Organization for Standardization, Geneva, Switzerland.

ISO. 2009. Agricultural Equipment. Radio-frequency Identification of Animals-Code structure. Draft Amendment ISO 11784:1996/ DAmd 2 (E). International Organization for Standardization, Geneva, Switzerland.

JRC (Joint Research Center). 2003. IDEA Project, large-scale project on livestock electronic identification. Final Report. v. 5.2. Accessed Dec. 15, 2009. http://idea.jrc.it/pages\%20idea/final\%20report. htm.

Lambooij, E., C. E. Van't Klooster, W. Rossing, A. C. Smits, and C. Pieterse. 1999. Electronic identification with passive transponders in veal calves. Comput. Electron. Agric. 24:81-90.

MAPA (Ministerio de Agricultura, Pesca y Alimentación). 2002. Informe final del Proyecto IDEA España (1998-2001). Anexo II: Informe técnico sobre pérdidas en ganado caprino. Accessed Dec. 20, 2009. http://ie.mapya.es/Experiencias/ANEXO-II\%20Informe\%20 Perdidas\%20en\%20Cabra.pdf.

MAPA (Ministerio de Agricultura, Pesca y Alimentación). 2007. Identificación Electrónica Animal: Experiencias del MAPA. MAPA, Madrid, Spain.

Pinna, W., P. Sedda, G. Moniello, and O. Ribó. 2006. Electronic identification of Sarda goats under extensive conditions in the island of Sardinia. Small Rumin. Res. 66:286-290. 
Raykov, T., and G. A. Marcoulides. 2004. Using the Delta Method for approximate interval estimation of parameter functions in SEM. Struct. Equ. Modeling 11:621-637.

Ribó, O., G. Caja, and R. Nehring. 1994. A note on electronic identification using transponders placed in permanent ruminal bolus in sheep and goats. Electronic identification of farm animals using implantable transponders. European Union General Directorate VI-FEOGA, Research Project, Final Report Vol. I, Exp. UAB01/2.6. European Commission, Brussels, Belgium.

San Miguel, O., G. Caja, R. Nehring, F. Miranda, J. A. Merino, V. Almansa, and M. J. Lueso. 2005. Results of the IDEA project on cattle, sheep and goats in Spain. Pages 357-359 in Performance Recording of Farm Animals State of the Art, 2004. ed. M. Guellouz, A. Dimitriadou and C. Mosconi. EAAP Pub. No 113. Wageningen Academic Publishers, Wageningen, the Netherlands.
Schuiling, H. J., J. Verkaik, G. Binnendijk, P. Hogewerf, D. Smits, and B. van der Fels. 2004. Elektronische oormerken voor I\&R bij schapen en geiten. PraktijkRapport Schapen 02. Accessed Dec. 20, 2009. http://edepot.wur.nl/37208.

Stewart, S. C., P. Rapnicki, J. R. Lewis, and M. Perala. 2007. Detection of low frequency external electronic identification devices using commercial panel readers. J. Dairy Sci. 90:4478-4482.

Teyssier, L., J. L. Gaubert, P. M. Bouquet, C. Maton, and F. Bocquier. 2003. Utilisation de petits bolus pour l'identification électronique des ovins: Évaluation du taux de rétention et des effects de changements de mode de conduite. Renc. Rech. Ruminants 10:117.

Wallace, L. E., J. A. Paterson, R. Clark, M. Harbac, and A. Kellom. 2008. Readability of thirteen different radio frequency identification ear tags by three different multi-panel reader systems for use in beef cattle. Prof. Anim. Sci. 24:384-391. 